\section{Novel therapeutic approaches in chondrosarcoma}

\author{
Genovefa Polychronidou ${ }^{\ddagger 1}$, Vasilios Karavasilis ${ }^{\ddagger, 1}$, Seth M Pollack², Paul H Huang ${ }^{3}$, \\ Alex Lee ${ }^{4} \&$ Robin L Jones ${ }^{* 4,5}$
}

\begin{abstract}
Chondrosarcoma is a malignant tumor of bones, characterized by the production of cartilage matrix. Due to lack of effective treatment for advanced disease, the clinical management of chondrosarcomas is exceptionally challenging. Current research focuses on elucidating the molecular events underlying the pathogenesis of this rare bone malignancy, with the goal of developing new molecularly targeted therapies. Signaling pathways suggested to have a role in chondrosarcoma include Hedgehog, Src, PI3k-Akt-mTOR and angiogenesis. Mutations in $I D H 1 / 2$, present in more than $50 \%$ of primary conventional chondrosarcomas, make the development of IDH inhibitors a promising treatment option. The present review discusses the preclinical and early clinical data on novel targeted therapeutic approaches in chondrosarcoma.
\end{abstract}

First draft submitted: 4 May 2016; Accepted for publication: 21 October 2016; Published online: 30 January 2017

Chondrosarcoma is a malignant tumor of bone that is characterized by the production of cartilage matrix by tumor cells but displays diverse histopathology and clinical behavior [1]. Following osteosarcoma, it is the second most frequent primary malignant tumor of bone [2], accounting for $20-27 \%$ of primary malignant bone neoplasms [3]. The most common anatomical location of origin is pelvis, followed by the proximal femur, proximal humerus, distal femur and ribs [4]. The vast majority (90\%) are conventional chondrosarcomas, either presenting de novo in the medulla of bone, or arising as a secondary tumor from pre-existing benign lesion such as enchondromas and osteochondromas. The remaining $10 \%$ are rare variants of chondrosarcoma, which include dedifferentiated, clear cell and mesenchymal chondrosarcomas. It remains a matter of debate whether myxoid chondrosarcoma represents a higher grade variant of conventional chondrosarcoma or should be considered a distinct disease entity [5]. Conventional chondrosarcomas are typically low or intermediate grade and are characterized by indolent clinical course and low metastatic potential. High-grade chondrosarcomas account for $5-10 \%$ of conventional chondrosarcomas and are associated with high metastatic potential and poor prognosis. The main site of metastatic disease is lung, while the regional lymph nodes and liver are much less commonly involved [6,7].

The cornerstone of the management of localized chondrosarcomas is surgical resection. Lowgrade tumors confined to the bone, in selected cases can be managed by extensive intralesional

'London Sarcoma Service, University College London Hospital, London, UK

${ }^{2}$ Fred Hutchinson Cancer Research Center, Seattle, WA, USA

3Division of Cancer Biology, The Institute of Cancer Research, London, UK

${ }^{4}$ Sarcoma Unit, Royal Marsden Hospital, London, UK

${ }^{5}$ Division of Clinical Studies, The Institute of Cancer Research, London, UK

*Author for correspondence: Tel.: +44 207808 2137; Fax: +44 207808 2113; robin.jones4@nhs.net

${ }^{\ddagger}$ Authors contributed equally

\section{KEYWORDS}

- chondrosarcoma $\bullet \mathrm{HDACls}$

- Hedgehog pathway

- IDH1/2 • novel agents • Src pathway $\bullet$ treatment 
curettage, with the aim of minimizing functional disability $[8,9]$, while high-grade tumors require wide, en-bloc local excision with negative margins [10]. The adequate surgical margin for low-grade intracompartmental chondrosarcomas is a matter of controversy, as some surgeons propose wide resection, while others believe that intralesional resection, followed by adjuvants, such as liquid nitrogen, phenol, cryotherapy, electrocautery and argon-beam laser is adequate [11]. Chondrosarcomas are inherently resistant to conventional chemo and radiation therapy. Proposed mechanisms of chemoresistance include low mitotic fraction and restricted drug penetration into tumor microenvironment as a result of poor vascularity and abundant hyaline-dense extracellular matrix [1,12]. The possible activation of multidrug resistance pumps and the increased expression of antiapoptotic factors have also been described to contribute to chemotherapy resistance $[12,13]$. However, some of the rare subtypes may be more responsive [12], for example, mesenchymal chondrosarcomas have been demonstrated to be sensitive to doxorubicin-based combination chemotherapy, based on modest clinical evidence from nonrandomized trials [14]. Stereotactic radiosurgery has been successfully employed for skull-base and spinal chondrosarcomas and proton radiotherapy has been used for chondrosarcoma of the skull base and cervical spine [15]. Likewise, retrospective evidence suggests that dedifferentiated chondrosarcoma managed with combination of surgery and chemotherapy may have a better outcome than those treated with surgery alone [16].

Due to the limited efficacy of available treatments, the clinical management of chondrosarcomas is challenging, and new therapeutic approaches are urgently needed. Current research focuses on elucidating the molecular events underlying the pathogenesis of this rare bone malignancy, aiming at the identification of new molecularly-targeted therapies, especially for chemotherapy refractory, inoperable or metastatic chondrosarcomas. Our objective in this review is to discuss the current research of pharmaceutical targets for novel therapeutic interventions (Figure 1).

The emerging role of $I D H$ mutations in chondrosarcoma

Over the last few years, growing evidence suggests that certain oncogenic alterations in pathways directly reprogram the metabolic activity of the cancer cell $[17,18]$. One of the best described genetic alterations linking oncogenesis and metabolism are mutations in the $I D H 1$ and $I D H 2$ genes. IDH proteins, encoded by the $I D H$ genes, catalyze the oxidative decarboxylation of isocitrate, producing $\alpha \mathrm{KG}$ and $\mathrm{CO} 2$ in the Krebs cycle. Mutations in the $I D H$ family of genes have been described in patients with a variety of cancers $[19,20]$. These mutations are known to produce $2 \mathrm{HG}$ from $\alpha \mathrm{KG}$ conversion. $2 \mathrm{HG}$ accumulates in the serum of the patients and inhibits the function of enzymes that are dependent on $\alpha K G$, leading to a hypermethylated state of DNA and histones, which results in different gene expression associated with tumorigenesis [20]. 2HG inhibits TET2 activity in vitro, which is a member of the TET family of $\alpha$ KG-dependent DNA modifying enzymes, and a DNA demethylation mediator. Thus, $2 \mathrm{HG}$ results in DNA hypermethylation, by inhibiting TET2-mediated DNA demethylation. 2HG also inhibits $\alpha$ KG-dependent JHKDMs. JHKDMs modify chromatin to regulate gene expression epigenetically. These enzymes, considered as tumor suppressors, have been associated with oncogenesis in various types of cancer [21].

Somatic mutations of the $I D H$ genes are present in around $87 \%$ of benign enchondromas and more than $50 \%$ of primary conventional chondrosarcomas [5,22]. These mutations have been linked to the enchondromatosis-associated nonhereditary Maffucci and Ollier syndromes. The high mutation frequency in enchondromas and the fact that they are early events suggest a causal role for $I D H 1$ or $I D H 2$ mutations in tumorigenesis in Ollier disease and Maffucci syndrome $[23,24]$.

IDH2 mutation has been shown to induce 2HG-dependent DNA hypermethylation in chondrosarcoma cells, resulting in inhibition of mesenchymal differentiation through epigenetic dysregulation. Treatment with the demethylating agent 5-azacytidine reversed this differentiation block, suggesting a potential route for therapeutic development [25]. Treatment of cells with AGI-5198, a specific inhibitor of mutant $I D H 1$, has been shown to reduce production of $2-\mathrm{HG}$ by up to $90 \%$ across a number of chondrosarcoma cell lines harboring endogenous IDH1 mutation. However, the effect of IDH1 inhibition on viability, proliferation and migration on these cells has been inconsistent between studies, suggesting there is further 


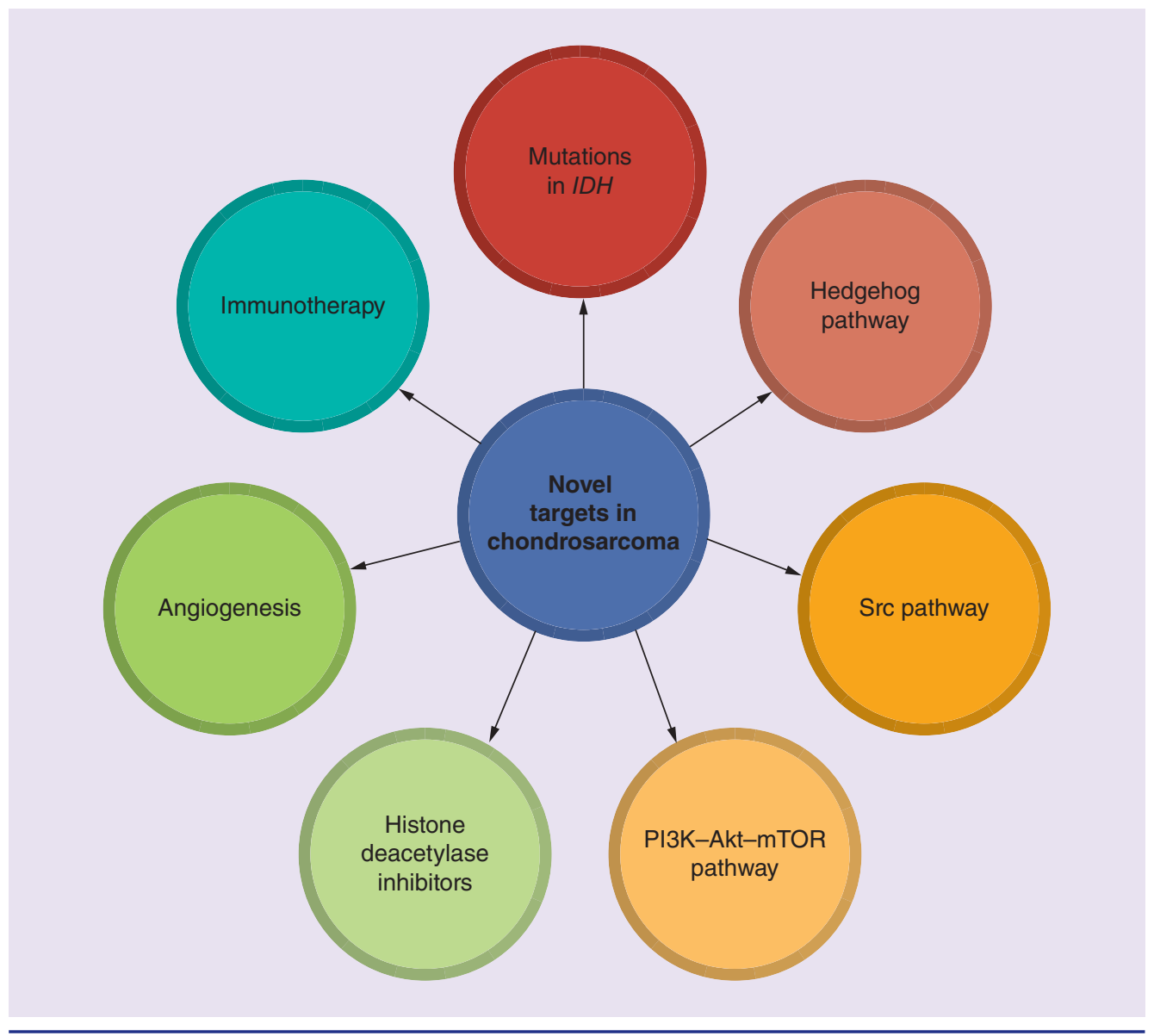

Figure 1. Novel targets in chondrosarcoma.

complexity to the role of epigenetic dysregulation in chondrosarcoma $[26,27]$.

Ongoing clinical trials are evaluating the clinical activity of novel IDH inhibitors. AG-221, an oral IDH2 inhibitor, is currently being tested in a Phase I/II, multicenter trial enrolling patients with advanced solid tumors, including glioma, angioimmunoblastic T-cell lymphoma and chondrosarcoma with an $I D H 2$ mutation (NCT02273739). The IDH inhibitors AG-881 and AG-120 are also under clinical evaluation in Phase I studies of advanced solid tumors that harbor an IDH1 and/or IDH2 mutation, including gliomas, cholangiocarcinomas and chondrosarcomas (NCT02481154/NCT02073994). Moreover, there is an ongoing Phase Ib, openlabel, single-center, nonrandomized clinical trial that evaluates the toxicity and efficacy of metformin in combination with chloroquine in IDH1/2 mutated patients with a glioma, intrahepatic cholangiocarcinoma or chondrosarcoma (NCT02496741). Based on the data described above, the development of IDH inhibitors is emerging as a promising treatment option on the horizon for patients with chondrosarcoma.

\section{Targeting the hedgehog pathway}

The Hedgehog signaling pathway is an important regulator of cell growth and differentiation during embryogenesis and is also involved in the maintenance of homeostasis in postembryonic tissues by regulating the differentiation of stem cells [28]. When extracellular hedgehog ligands binds to PTCH1, a transmembrane receptor, PTCH1-mediated inhibition of signaling by SMO is prevented [29]. Activation of the SMO results in the activation of transcription factors encoded by GLI family zinc finger and consequent expression of hedgehog target genes, including GLII and PTCH1 [30].

The Indian Hedgehog ( $\mathrm{IHH}) /$ parathyroid hormone-related peptide pathway (PTHrP) has a crucial role to chondrocyte differentiation and emerging evidence proposes that constitutive IHH signaling has a key role in the pathogenesis of chondrosarcomas [31]. Aberrant activation 
of this pathway leads to constant signals from $\mathrm{IHH}$, which induce chondrocyte proliferation and secretion of PTHrP from chondrocytes to the perichondrial space. There, PTHrP mediates inhibition of chondrocyte differentiation and apoptosis, therefore maintaining the cells in their proliferative state. The deregulation of the pathway also leads to high expression levels of its intramembrane receptor PTCH1 and its downstream transcription factor GLI [31].

A recent study evaluated in primary chondrosarcoma xenografts the activity of IPI-926, a potent oral Hh-inhibitor, on tumor formation and growth. The results demonstrated that IPI926 had significant antitumor effects against human chondrosarcoma cell lines [32]. IPI-926 had previously shown activity in xenograft models of basal cell carcinoma and medulloblastoma, tumors which are also dependent on constitutive Hh signaling $[32,33]$. In another study, treatment of human chondrosarcoma SW1353 cells with the $\mathrm{HH}$ pathway inhibitor-4 (HPI-4) significantly decreased proliferation, invasion and migration capacity [34]. An additional study demonstrated that knockdown of GLI1 expression by siRNA downregulated the expression of key Hh pathway members, including PTCH1 and SMO, and restrained the growth and survival of the treated chondrosarcoma cells [35]. The results of these studies provide the rationale for investigating Hh pathway blockade as a novel therapeutic option for patients with chondrosarcoma presenting aberrant activation of the $\mathrm{HH}$ signaling pathway.

While preclinical data of IPI-926 (saridegib) have demonstrated activity in a wide range of malignancies, the clinical data of a Phase II randomized placebo-controlled trial in patients with advanced chondrosarcoma have been discouraging [36]. Likewise, treatment with GDC-0449 (vismodegib) tested in a single-arm Phase II trial, although suggesting some activity in a subset of patients with progressive grade 1 or 2 conventional chondrosarcoma, did not meet the primary end point of 6-month clinical benefit rate [37]. These disappointing clinical results may indicate a ligand-independent activation of the Hh pathway in chondrosarcoma, which might occur with loss-of-function mutation of PTCH or gain-of-function mutation of SMO. Surrogate markers for selection of patients more likely to benefit from such targeted treatments could lead to more favorable outcomes in future studies [37].

\section{The SRC pathway}

Src and other members of the Src family of protein tyrosine kinases play key roles in regulating the transduction of signals originating from cell surface receptors [38,39]. The activation of the c-Src pathway has been observed in several tumors and has been linked to intratumoral signaling involved in cell survival, angiogenesis, proliferation and migration $[39,40]$. The Src was found to be activated in human sarcoma tissues (leiomyosarcoma, high-grade osteosarcoma) and sarcoma cell lines (osteosarcoma, Ewing's sarcoma, rhabdomyosarcoma) [41], while in synovial sarcoma cells it has been identified as one of the most strongly phosphorylated kinases [42]. Thereby, Src has been proposed to play an important role in signal transduction in human sarcomas, including osteosarcoma, rhabdomyosarcoma, leiomyosarcoma, fibrosarcoma and Ewing sarcoma [43].

Based on these findings, Src became an enticing target for drug development and a number of Src inhibitors, including dasatinib (BMS354825) are currently at various stages in the development process [44]. Dasatinib is a small molecule inhibitor that targets a broad range of tyrosine kinases, including ABL, SRC family kinases, c-KIT and PDGFR- $\alpha$ and $-\beta$ [45]. Inhibition of the Src pathway by dasatinib in sarcoma cell lines demonstrated therapeutic benefit, preventing the growth and metastasis [41,46], while in another study it resulted in decreased cell viability in seven of nine chondrosarcoma cell cultures [46].

Although dasatinib as a single agent has shown some preclinical activity in chondrosarcomas, there is an accumulating body of evidence to support the use of dasatinib in combination with other antineoplastic drugs [47-50]. Oosterwijk et al. showed that dasatinib was effective in overcoming chemoresistance and successfully sensitized chondrosarcoma for doxorubicin treatment, especially in TP53 mutant chondrosarcoma cell lines [51]. On the contrary, the SARC009 trial, a Phase II study of dasatinib in patients with previously treated, high-grade, advanced sarcomas, including chondrosarcomas concluded that dasatinib was inactive as a single agent [52]. Thus, Src inhibitors might offer a new approach in the treatment of sarcoma in combination with other chemotherapeutic regimens.

\section{Targeting the PI3K-Akt-mTOR pathway}

The PI3K-Akt-mTOR pathway has a significant role in various normal cellular processes 
including cell proliferation, growth and survival [53]. The activation of the pathway is initiated by ligand activation of receptor tyrosine kinases (RTKs), such as the IGF-1R and PDGFR- $\alpha$ and $-\beta$. Aberrant activation of the PI3K pathway has been implicated in tumorigenesis of various cancers, and increased activation of this pathway is often associated with resistance to cytotoxic therapies [54,55]. Due to these observations and its critical contribution in cell growth and survival, this pathway became a promising target for pharmacologic intervention. The rapamycin analogs everolimus and temsirolimus, which inhibit mTORC1, were the first PI3K pathway-targeted agents approved for the treatment of renal cancer. Subsequently, an increasing number of PI3K pathway inhibitors have undergone clinical evaluation [56].

In a recent study, multiple RTKs were found to be activated in chondrosarcoma cells and to exhibit crucial roles in mediating cell growth [57]. Strong phosphorylation of S6 kinase, a surrogate of PI3K-mTOR pathway activity, was detected in $69 \%$ of conventional chondrosarcoma and $44 \%$ of dedifferentiated chondrosarcoma clinical samples, suggesting that activation of the PI3K-Akt-mTOR pathway in cell lines is clinically relevant. The study links RTK activation in chondrosarcoma cells to PI3K-Akt-mTOR signaling by showing that RTK inhibitors suppress Akt and S6 kinase phosphorylation. Treatment with BEZ235, a dual PI3K/mTOR inhibitor, significantly reduced the growth of chondrosarcoma cell lines and in a xenograft model of chondrosarcoma, suggesting that inhibition of the PI3K/mTOR pathway represents a rational therapeutic strategy [57].

Another study investigated the antitumor effect of doxorubicin and/or everolimus as a single agent or in combination in a rat chondrosarcoma model, both in macroscopic and in microscopic residual disease following $\mathrm{R} 1 \mathrm{resec}-$ tion of the implanted tumor [58]. Doxorubicin as a single agent was inactive, in terms of inhibiting tumor growth, while everolimus had a major suppressant effect on tumor progression in macroscopic tumors and significantly delayed or prevented tumor recurrence in rats with microscopic residual disease. The combination with doxorubicin did not exhibit additive synergistic effect. These preclinical data support the use of mTOR inhibitors as a single agent in treating chondrosarcoma patients, and moreover the use of everolimus as adjuvant long-term therapy in chondrosarcoma patients following surgery [58]. A retrospective study of ten patients with unresectable chondrosarcoma, who were treated with the mTOR inhibitor sirolimus in combination with cyclophosphamide, showed that the regimen was well tolerated with disease control rate of $70 \%$, implying meaningful clinical activity [59]. A recently published Phase I/II clinical trial evaluated the ability of temsirolimus to potentiate the cytotoxic effect of liposomal doxorubicin [60]. Reported Phase I data have demonstrated safety of the combination in adult and pediatric patients. The Phase II expansion part of this study is ongoing [60]. A Phase II study of everolimus in patients with primary or relapsed chondrosarcomas is ongoing, aiming to evaluate the efficacy and safety of everolimus as neo-adjuvant therapy (NCT02008019).

The IGF-1R-mediated activation of the PI3K-Akt pathway is a recognized mechanism of intrinsic mTORC1 inhibitor resistance described in a range of malignancies, including sarcoma [61-63]. IGF-1R overexpression has been reported in a number of sarcoma subtypes $[64,65]$. Preclinical data indicate that combination of mTOR with IGF-1R inhibitors results in suppression of Akt activation and enhancement of drug-induced antiproliferative effects [63]. This knowledge led to the design of several early phase clinical trials evaluating the combined mTORC1 and IGF-1R inhibition in sarcoma patients [6668], with early results indicating that the combination may have greater clinical efficacy than treatment with each agent alone [67]. PDGFR- $\alpha$ is another RTK that can mediate rapamycininduced Akt phosphorylation in sarcoma cell lines in a subset of tumors, and therefore, could be an attractive therapeutic target to inhibit in combination with mTORC [69]. Moreover, kinome analysis of chondrosarcoma tumors has shown that among others, the PDGFR pathway is overactive in chondrosarcomas [46].

A Phase II trial of the R1507, an IGF-1R inhibitor, enrolled patients with recurrent or refractory bone and soft tissue sarcoma and demonstrated that R1507 is safe and well tolerated but has limited clinical activity [70]. Another Phase II study investigated patients with previously treated advanced or metastatic bone and soft tissue sarcomas, treated with the IGF-1R inhibitor cixutumumab (IMC-A12), a fully human IgG1 monoclonal antibody. The results indicated that cixutumumab was well tolerated and patients with adipocytic sarcoma may 
benefit from the treatment [65]. An additional Phase I clinical trial is exploring the safety, efficacy and best dose of cixutumumab given in combination with doxorubicin in patients with unresectable, locally advanced or metastatic soft tissue sarcoma (NCT00720174).

The Italian Sarcoma Group enrolled 26 patients in a Phase II trial of imatinib, a multi tyrosine-kinase inhibitor including inhibition of PDGFR, in patients with recurrent nonresectable chondrosarcomas, which all demonstrated immunohistochemical expression of PDGFR. Although imatinib was well-tolerated, the trial failed to demonstrate meaningful clinical activity [71]. The efficacy of imatinib is also under evaluation in the NCT00928525 openlabel trial of Patients with Desmoid Tumors and Chondrosarcoma, expressing PDGFR- $\alpha$ and $-\beta$.

\section{Histone deacetylase inhibitors}

Modification of histones by acetylation is a key mechanism for the regulation of gene expression and plays a central role in determining cellular differentiation state. Dysregulation of histone modification is commonly found across a broad range of cancer types and has emerged as an important therapeutic target. The established knowledge that epigenetic alterations can change gene expression and consequently phenotype, disturb homeostasis and contribute to tumor growth has made the histone deacetylase inhibitors (HDACIs) an attractive class of anticancer therapy $[72,73]$.

The acetylation status of histones, as it alters chromatin architecture, has an important role in modifying gene expression [72]. Abnormal histone acetylation status has been linked to the development of various diseases, including cancer. Loss of acetylation at Lys16 and trimethylation at Lys 20 of histone $\mathrm{H} 4$ constitutes a common finding in cancer in a variety of cancers [73].

Currently, there are four HDACIs approved by the US FDA, for the treatment of refractory cutaneous T-cell lymphoma (vorinostat/ZOLINZA and romidepsin/ISTODAX ${ }^{\circledR}$ ), peripheral T-cell lymphoma (belinostat/Beleodaq and romidepsin) [74-77], relapsed and/or refractory multiple myeloma (panobinostat/FARYDAK ${ }^{\circledR}$ ), as well as several clinical trials investigating novel HDACIs in various malignancies (Table 1).

Based on preclinical data showing that HDACIs induce growth arrest, apoptosis and differentiation in sarcoma cancer stem cells [78], as well as in chondrosarcoma cells [79], there is a Phase II clinical trial of a single agent Romidepsin in metastatic or unresectable soft tissue sarcomas (NCT00112463). Compelling preclinical work and early signals of clinical efficacy from early phase clinical trials indicate the likely worth of continued investigation of this class of drugs in chondrosarcoma [80].

\section{The role of angiogenesis}

Angiogenesis is a hallmark trait required for cancer development, progression and metastasis [81], and has proven to be an important therapeutic target over the past two decades. There is growing evidence from preclinical data, implicating angiogenesis with the pathogenesis of chondrosarcomas [82-86]. In addition, vascularization increases with increasing histological grade [87]. SU6668 is an inhibitor of the RTKs Flk-1/KDR (VEGR2), PDGFR- $\beta$ and FGFR1. SU6668 induced a growth inhibition of chondrosarcoma animal models, which appears to be linked to the antiangiogenic effects of SU6668 [82]. Inhibition of COX-2 by celecoxib, a COX-2 inhibitor, which is another mediator of angiogenesis, has been tested in four high-grade chondrosarcoma cell lines. Treatment with celecoxib minimized cell viability in vitro. Conventional central and peripheral cartilaginous tumors from 66 patients were immunohistochemically assessed for COX-2 protein expression and $65 \%$ were found positive. The initial response in tumor growth supported a role for celecoxib, although a relapse in tumor growth was noticed after 6 weeks of treatment [88].

The NCT01330966 Phase II study is investigating the efficacy and safety of the single agent pazopanib in patients with unresectable or metastatic chondrosarcoma. Pazopanib is a potent and selective multitargeted RTK inhibitor, which inhibits c-KIT, FGFR, PDGFR and VEGFR among other enzymes [89]. Additionally, the NCT02066285 Phase II trial is also testing pazopanib in patients with unresectable or metastatic solitary fibrous tumor and extraskeletal myxoid chondrosarcoma. Regorafenib is another oral multikinase inhibitor, which targets angiogenic, stromal and oncogenic RTKs and is currently being tested in a Phase II study in patients with metastatic bone sarcomas (NCT02389244).

\section{Other targeted treatments}

Estrogen receptors are key regulators of the longitudinal skeletal growth that is initiated from 


\begin{tabular}{|c|c|c|c|c|c|}
\hline Study ID & Agent & Mechanism of action & Study design & Study population & Status \\
\hline \multicolumn{6}{|c|}{ Targeting IDH mutations } \\
\hline NCT02273739 & AG-221 & Oral IDH2 inhibitor & Phase I/II & $\begin{array}{l}\text { Advanced solid tumors, } \\
\text { including chondrosarcoma, } \\
\text { and angioimmunoblastic T-cell } \\
\text { lymphoma, with an IDH2 mutation }\end{array}$ & $\begin{array}{l}\text { Ongoing, but } \\
\text { not recruiting } \\
\text { participants }\end{array}$ \\
\hline NCT02481154 & AG-881 & Oral IDH inhibitor & Phase I & $\begin{array}{l}\text { Advanced solid tumors, including } \\
\text { chondrosarcoma, with an IDH1 and/ } \\
\text { or IDH2 mutation }\end{array}$ & Recruiting \\
\hline NCT02073994 & AG-120 & Oral IDH inhibitor & Phase I & $\begin{array}{l}\text { Advanced solid tumors, including } \\
\text { chondrosarcoma, with an IDH1 } \\
\text { mutation }\end{array}$ & Recruiting \\
\hline NCT02496741 & $\begin{array}{l}\text { Metformin plus } \\
\text { chloroquine }\end{array}$ & $\begin{array}{l}\text { Oral antidiabetic (metformin) } \\
\text { and oral antimalarial }\end{array}$ & Phase lb & $\begin{array}{l}\text { IDH1/2 mutated patients } \\
\text { with a glioma, intrahepatic } \\
\text { cholangiocarcinoma or } \\
\text { chondrosarcoma. }\end{array}$ & Recruiting \\
\hline \multicolumn{6}{|c|}{ PI3K-Akt-mTOR pathway } \\
\hline NCT02008019 & Everolimus & mTOR inhibitor & Phase II & $\begin{array}{l}\text { Neo-adjuvant therapy in patients } \\
\text { with primary or relapsed } \\
\text { chondrosarcomas }\end{array}$ & Recruiting \\
\hline NCT00720174 & $\begin{array}{l}\text { Cixutumumab } \\
\text { plus doxorubicin } \\
\text { hydrochloride }\end{array}$ & IGF-1R inhibitor & Phase I & $\begin{array}{l}\text { Patients with unresectable, locally } \\
\text { advanced, or metastatic soft tissue } \\
\text { sarcoma }\end{array}$ & Completed \\
\hline NCT00928525 & Imatinib & $\begin{array}{l}\text { A multi tyrosine kinase } \\
\text { inhibitor including inhibition } \\
\text { of PDGFR }\end{array}$ & Phase II & $\begin{array}{l}\text { Patients with advanced desmoid } \\
\text { tumor and chondrosarcoma } \\
\text { expressing the PDGFR- } \alpha \text { and }-\beta\end{array}$ & $\begin{array}{l}\text { Ongoing, but } \\
\text { not recruiting } \\
\text { participants }\end{array}$ \\
\hline \multicolumn{6}{|l|}{ HDAC inhibitors } \\
\hline NCT00112463 & Romidepsin & Histone deacetylase inhibitor & Phase II & $\begin{array}{l}\text { Patients with metastatic or } \\
\text { unresectable soft tissue sarcoma }\end{array}$ & Unknown \\
\hline \multicolumn{6}{|c|}{ Targeting angiogenesis } \\
\hline NCT01330966 & Pazopanib & $\begin{array}{l}\text { Selective multi-targeted } \\
\text { receptor tyrosine kinase } \\
\text { inhibitor }\end{array}$ & Phase II & $\begin{array}{l}\text { Unresectable or metastatic } \\
\text { chondrosarcoma }\end{array}$ & $\begin{array}{l}\text { Ongoing, but } \\
\text { not recruiting } \\
\text { participants }\end{array}$ \\
\hline NCT02066285 & Pazopanib & $\begin{array}{l}\text { Selective multi-targeted } \\
\text { receptor tyrosine kinase } \\
\text { inhibitor }\end{array}$ & Phase II & $\begin{array}{l}\text { Patients with unresectable } \\
\text { or metastatic solitary fibrous } \\
\text { tumor and extraskeletal myxoid } \\
\text { chondrosarcoma }\end{array}$ & Recruiting \\
\hline NCT02389244 & Regorafenib & $\begin{array}{l}\text { Multi-kinase inhibitor, which } \\
\text { targets angiogenic, stromal } \\
\text { and oncogenic receptor } \\
\text { tyrosine kinase }\end{array}$ & Phase II & $\begin{array}{l}\text { Patients with metastatic bone } \\
\text { sarcomas, including intermediate or } \\
\text { high-grade chondrosarcomas }\end{array}$ & Recruiting \\
\hline
\end{tabular}

chondrocyte differentiation and proliferation in the epiphyseal growth plate of long bones [90]. Expression of estrogen and aromatase receptors has been identified in chondrosarcomas [90,91], suggesting that these tumors could be susceptible to estrogen and aromatase signaling inhibition [90]. However, in one study, in vitro and pilot in vivo studies showed no effect of any of the aromatase inhibitors on proliferation of conventional chondrosarcomas [91].

The monoclonal antibody PRO95780 (Genentech) is a proapoptotic receptor agonist, which specifically targets DR5, it activates the extrinsic apoptotic pathway and found to induce apoptosis in a plethora of human cancer cell lines and xenograft models $[92,93]$. PRO95780 targets DR5, which is expressed in a broad spectrum of hematologic malignancies and solid tumors [94,95]. A Phase I study of PRO95780 in patients with advanced malignancies reported a minor response in a chondrosarcoma case [96], although an another Phase II study of PRO95780 in patients with advanced chondrosarcoma has been terminated 
due to lack of efficacy in this population (NCT00543712).

INI-1/hSNF5 is a tumor suppressor gene, encoding a subunit of the SWI/SNF chromatin remodeling complex and is widely expressed in most normal cells. Mutations or deletions of INI-1/hSNF5 have been described in malignant rhabdoid tumors and epithelioid sarcomas, including extraskeletal myxoid chondrosarcomas [97]. The histone-lysine $\mathrm{N}$-methyltransferase enzyme EZH2 is encoded by the EZH2 gene and is involved in suppressing gene expression through methylation of $\mathrm{H} 3 \mathrm{~K} 27$. EZH2 mutations or overexpressions are implicated in tumorigenesis of various cancers and correlate with poor prognosis thus, EZH2 has been an attractive target for anticancer therapy [98]. The EZH2 inhibitor, Tazemetostat is under clinical evaluation in a Phase II study, enrolling adult patients with INII-negative tumors - including extraskeletal myxoid chondrosarcomas or relapsed/refractory synovial sarcoma (NCT02601950). Additionally, tazemetostat is being tested in a Phase I study of pediatric population with relapsed or refractory INI1-negative tumors or synovial sarcoma (NCT02601937).

Immunotherapy with immune checkpoint inhibition is an area of interest that is currently being elucidated in numerous malignancies, including sarcoma. PD-1 and its ligand (PDL1) are key suppressors of the cytotoxic immune response, and their interaction results in a downregulation of the T-cell response. Blockade of the interaction between PD-1 and PD-L1 has been reported to have impressive antitumor effect. Kostine et al. reported an analysis of PD-L1 protein expression in a series of conventional, mesenchymal, clear cell and dedifferentiated chondrosarcomas [99]. Only dedifferentiated chondrosarcomas displayed PD-L1 positivity, which in association with immune-infiltrating cells and HLA class I expression in nearly $50 \%$ of the dedifferentiated chondrosarcomas provided rationale for testing $\mathrm{PD}-1 / \mathrm{PD}-\mathrm{L} 1$-targeted therapies in these patients [99]. Preliminary results of a Phase II study (SARC028) of the anti-PD1 antibody pembrolizumab (MK-3475) in patients with advanced soft tissue and bone sarcomas showed that $33 \%$ of patients with undifferentiated pleomorphic sarcoma and dedifferentiated liposarcoma had a tumor size shrinkage, while one out of the six patients enrolled with dedifferentiated chondrosarcoma exhibited partial tumor remission. These results imply that further investigations are warranted in these sarcoma types [100].

\section{Conclusion}

The past few years research focused on elucidating the molecular events underlying the pathogenesis of chondrosarcoma has led to the identification of several new potential therapeutic targets. Most of these targets demonstrated meaningful antitumor activity in preclinical studies, although the results in early phase clinical studies has been inconsistent. Future studies should further explore the utility of these candidate molecularly targeted therapies in the different subgroups of chondrosarcoma patients.

\section{Future perspective}

As previously described, chondrosarcoma has a diverse pattern behavior, ranging from slowgrowing nonmetastasizing lesions to aggressive metastasizing sarcomas. In the past, the modalities that were used to treat these rare tumors were surgical resection, as the mainstay of treatment and chemo-radiotherapy with rather discouraging results. In our site (The Royal Marsden Hospital, Sarcoma Unit), we have treated ten patients with antiangiogenic agents with durable disease stabilization, in patients with previously progressing metastatic disease. We are currently in the process of publishing this case series, although further work with these agents is clearly needed. As it is crucial to identify and develop effective adjuvant treatments, the results of the current research are being awaited with great interest, so as to achieve in the future a better clinical outcome to this rare entity.

\section{Financial \& competing interests disclosure}

The authors have no relevant affiliations or financial involvement with any organization or entity with a financial interest in or financial conflict with the subject matter or materials discussed in the manuscript. This includes employment, consultancies, honoraria, stock ownership or options, expert testimony, grants or patents received or pending, or royalties.

No writing assistance was utilized in the production of this manuscript.

\section{Open access}

This work is licensed under the Creative Commons Attribution-NonCommercial 4.0 Unported License. To view a copy of this license, visit http://creativecommons.org/ licenses/by-nc-nd/4.0/ 


\section{EXECUTIVE SUMMARY}

- Chondrosarcoma displays diverse histopathology and clinical behavior. The clinical management is exceptionally challenging as they are inherently resistant to conventional chemo and radiation therapy, therefore new therapeutic approaches are urgently needed.

\section{The emerging role of IDH mutations in chondrosarcoma}

- Preclinical data indicate antitumor activity of IDH inhibitors in chondrosarcoma cell lines. Ongoing early phase clinical trials are evaluating the clinical activity of novel IDH inhibitors in patients with advanced solid tumors, including chondrosarcoma with an IDH1 and/or IDH2 mutation.

\section{Targeting the hedgehog pathway}

- Emerging evidence proposes constitutive Indian Hedgehog signaling to have a key role in the pathogenesis of chondrosarcomas. However, the clinical data of a Phase II trial of IPI-926 (saridegib) in patients with advanced chondrosarcoma have been discouraging, although preclinical data have demonstrated activity in a wide range of malignancies.

\section{The SRC pathway}

- Src has been proposed to play an important role in signal transduction in human sarcomas and a number of Src inhibitors, including dasatinib (BMS354825) are currently at various stages in the development process.

- Dasatinib has shown some preclinical activity in chondrosarcomas as a single agent, but there is, also, evidence to support the use of dasatinib in combination with other antineoplastic drugs, for example, doxorubicin.

\section{Targeting the PI3K-Akt-mTOR pathway}

- Preclinical data indicate that inhibition of the PI3K/Akt/mTOR pathway has suppressant effect on chondrosarcoma tumor progression.

- Several early phase clinical trials are evaluating the combined mTORC1 and IGF-1R inhibition in sarcoma patients, with early results indicating that the combination may have greater clinical efficacy than treatment with each agent alone.

\section{Histone deacetylase inhibitors}

- Preclinical data show that histone deacetylase inhibitors induce growth arrest, apoptosis and differentiation in sarcoma cancer stem cells, as well as in chondrosarcoma cells. There is an ongoing Phase Il clinical trial of the histone deacetylase inhibitors Romidepsin in metastatic or unresectable soft tissue sarcomas (NCT00112463).

\section{The role of angiogenesis}

- Evidence from preclinical data implicates angiogenesis with the pathogenesis of chondrosarcomas, while angiogenesis inhibitors show tumor growth inhibition in chondrosarcoma animal models and cell lines.

\section{Future perspective}

- A plethora of molecularly targeted therapies are under clinical evaluation in patients with chondrosarcoma, aiming to a more personalized and effective treatment approach.

\section{References}

Papers of special note have been highlighted as:

- of interest; $\bullet$ of considerable interest

1 Bovée JVMG, Cleton-Jansen A-M, Taminiau AHM, Hogendoorn PCW. Emerging pathways in the development of chondrosarcoma of bone and implications for targeted treatment. Lancet Oncol. 6(8), 599-607 (2005).

2 Samuel AM, Costa J, Lindskog DM. Genetic alterations in chondrosarcomas - keys to targeted therapies? Cell Oncol. (Dordr.) 37(2) 95-105 (2014).
3 Murphey MD, Walker EA, Wilson AJ, Kransdorf MJ, Temple HT, Gannon FH. From the archives of the AFIP: imaging of primary chondrosarcoma: radiologicpathologic correlation. Radiographics 23(5), 1245-1278 (2003).

4 Mavrogenis AF, Angelini A, Drago G, Merlino B, Ruggieri P. Survival analysis of patients with chondrosarcomas of the pelvis. J. Surg. Oncol. 108(1), 19-27 (2013).

5 Meijer D, De Jong D, Pansuriya TC et al. Genetic characterization of mesenchymal, clear cell, and dedifferentiated chondrosarcoma. Genes Chromosomes Cancer 51(10), 899-909 (2012).

6 Hartley AL, Blair V, Harris M et al. Sarcomas in north west England: II. Incidence. Br. J. Cancer 64(6), 1145-1150 (1991).

7 Van Oosterwijk JG, Anninga JK, Gelderblom $\mathrm{H}$, Cleton-Jansen AM, Bovee JV. Update on targets and novel treatment options for high-grade osteosarcoma and chondrosarcoma. Hematol. Oncol. Clin. North Am. 27(5), 1021-1048 (2013).

8 Hickey M, Farrokhyar F, Deheshi B, Turcotte $\mathrm{R}$, Ghert M. A systematic review and meta-analysis of intralesional versus wide 
resection for intramedullary grade I chondrosarcoma of the extremities. Ann. Surg. Oncol. 18(6), 1705-1709 (2011).

9 Aarons C, Potter BK, Adams SC, Pitcher JD Jr, Temple HT. Extended intralesional treatment versus resection of low-grade chondrosarcomas. Clin. Orthop. Relat. Res. 467(8), 2105-2111 (2009).

10 Fiorenza F, Abudu A, Grimer RJ et al. Risk factors for survival and local control in chondrosarcoma of bone. J. Bone Joint Surg. Br. 84(1), 93-99 (2002).

11 Angelini A, Guerra G, Mavrogenis AF, Pala E, Picci P, Ruggieri P. Clinical outcome of central conventional chondrosarcoma. J. Surg. Oncol. 106(8), 929-937 (2012).

12 Van Oosterwijk JG, Herpers B, Meijer D et al. Restoration of chemosensitivity for doxorubicin and cisplatin in chondrosarcoma in vitro: $\mathrm{BCL}-2$ family members cause chemoresistance. Ann. Oncol. 23(6), 1617-1626 (2012).

13 Wyman JJ, Hornstein AM, Meitner PA et al. Multidrug resistance-1 and p-glycoprotein in human chondrosarcoma cell lines: expression correlates with decreased intracellular doxorubicin and in vitro chemoresistance. J. Orthop. Res. 17(6), 935-940 (1999).

14 Frezza AM, Cesari M, Baumhoer D et al. Mesenchymal chondrosarcoma: prognostic factors and outcome in 113 patients. A European Musculoskeletal Oncology Society study. Eur. J. Cancer 51(3), 374-381 (2015).

15 Mavrogenis AF, Gambarotti M, Angelini A et al. Chondrosarcomas revisited. Orthopedics 35(3), e379-e390 (2012).

16 Van Maldegem AM, Bovee JV, Gelderblom $\mathrm{H}$. Comprehensive analysis of published studies involving systemic treatment for chondrosarcoma of bone between 2000 and 2013. Clin. Sarcoma Res. 4, 11 (2014).

17 Liu L, Ulbrich J, Muller J et al. Deregulated MYC expression induces dependence upon AMPK-related kinase 5. Nature 483(7391), 608-612 (2012).

18 Wang PY, Ma W, Park JY et al. Increased oxidative metabolism in the Li-Fraumeni syndrome. N. Engl. J. Med. 368(11), 1027-1032 (2013).

19 Bleeker FE, Molenaar RJ, Leenstra S. Recent advances in the molecular understanding of glioblastoma. J. Neurooncol. 108(1), 11-27 (2012).

20 Ward PS, Patel J, Wise DR et al. The common feature of leukemia-associated IDHI and $I D H 2$ mutations is a neomorphic enzyme activity converting alpha-ketoglutarate to 2-hydroxyglutarate. Cancer Cell 17(3), 225-234 (2010).

21 Molenaar RJ, Radivoyevitch T, Maciejewski JP, Van Noorden CJ, Bleeker FE. The driver and passenger effects of isocitrate dehydrogenase 1 and 2 mutations in oncogenesis and survival prolongation. Biochim. Biophys. Acta 1846(2), 326-341 (2014).

22 Schaap FG, French PJ, Bovee JV. Mutations in the isocitrate dehydrogenase genes $I D H 1$ and $I D H 2$ in tumors. Adv. Anat. Pathol. 20(1), 32-38 (2013).

23 Amary MF, Damato S, Halai D et al. Ollier disease and Maffucci syndrome are caused by somatic mosaic mutations of $I D H 1$ and IDH2. Nat. Genet. 43(12), 1262-1265 (2011).

24 Pansuriya TC, Van Eijk R, D'adamo P et al. Somatic mosaic $I D H 1$ and $I D H 2$ mutations are associated with enchondroma and spindle cell hemangioma in Ollier disease and Maffucci syndrome. Nat. Genet. 43(12), 1256-1261 (2011).

$25 \mathrm{Lu}$ C, Venneti S, Akalin A et al. Induction of sarcomas by mutant $\mathrm{IDH} 2$. Genes Dev. 27(18), 1986-1998 (2013).

26 Li L, Paz AC, Wilky BA et al. Treatment with a small molecule mutant IDH1 inhibitor suppresses tumorigenic activity and decreases production of the oncometabolite 2-hydroxyglutarate in human chondrosarcoma cells. PLoS ONE 10(9), e0133813 (2015).

- A study that demonstrates antitumor activity of an IDH1 inhibitor in human chondrosarcoma cell lines, and suggests that D-2HG is a potential biomarker for $I D H$ mutations in chondrosarcoma cells.

27 Suijker J, Oosting J, Koornneef A et al. Inhibition of mutant $I D H I$ decreases D-2-HG levels without affecting tumorigenic properties of chondrosarcoma cell lines. Oncotarget 6(14), 12505-12519 (2015).

28 Zhang Y, Kalderon D. Hedgehog acts as a somatic stem cell factor in the Drosophila ovary. Nature 410(6828), 599-604 (2001).

29 Daya-Grosjean L, Couve-Privat S. Sonic Hedgehog signaling in basal cell carcinomas. Cancer Lett. 225(2), 181-192 (2005).

30 Rubin LL, De Sauvage FJ. Targeting the Hedgehog pathway in cancer. Nat Rev. Drug Discov. 5(12), 1026-1033 (2006).

31 Tiet TD, Hopyan S, Nadesan P et al. Constitutive Hedgehog signaling in chondrosarcoma up-regulates tumor cell proliferation. Am. J. Pathol. 168(1), 321-330 (2006).
32 Campbell VT, Nadesan P, Ali SA et al. Hedgehog pathway inhibition in chondrosarcoma using the smoothened inhibitor IPI-926 directly inhibits sarcoma cell growth. Mol. Cancer Ther. 13(5), 1259-1269 (2014).

33 Lee MJ, Hatton BA, Villavicencio EH et al. Hedgehog pathway inhibitor saridegib (IPI-926) increases lifespan in a mouse medulloblastoma model. Proc. Natl Acad. Sci. USA 109(20), 7859-7864 (2012).

34 Xiang W, Jiang T, Guo F et al. Hedgehog pathway inhibitor- 4 suppresses malignant properties of chondrosarcoma cells by disturbing tumor ciliogenesis. Oncol. Rep. 32(4), 1622-1630 (2014).

35 Sun Y, Guo W, Ren T et al. Gli1 inhibition suppressed cell growth and cell cycle progression and induced apoptosis as well as autophagy depending on ERK1/2 activity in human chondrosarcoma cells. Cell Death Dis. 5, e979 (2014)

36 Infinity stops Phase 2 trials of saridegib in chondrosarcoma and Myelofibrosis [press release]. Business Wire, Cambridge, MA, USA, 18 Jun 2012.

37 Italiano A, Le Cesne A, Bellera C et al. GDC-0449 in patients with advanced chondrosarcomas: a French Sarcoma Group/ US and French National Cancer Institute Single-Arm Phase II Collaborative Study. Ann. Oncol. 24(11), 2922-2926 (2013).

38 Parsons SJ, Parsons JT. Src family kinases, key regulators of signal transduction. Oncogene 23(48), 7906-7909 (2004).

39 Wheeler DL, Iida M, Dunn EF. The role of Src in solid tumors. Oncologist 14(7), 667-678 (2009).

40 Dehm SM, Bonham K. SRC gene expression in human cancer: the role of transcriptional activation. Biochem. Cell Biol. 82(2), 263-274 (2004).

41 Shor AC, Keschman EA, Lee FY et al. Dasatinib inhibits migration and invasion in diverse human sarcoma cell lines and induces apoptosis in bone sarcoma cells dependent on SRC kinase for survival. Cancer Res. 67(6), 2800-2808 (2007).

42 Michels S, Trautmann M, Sievers E et al. SRC signaling is crucial in the growth of synovial sarcoma cells. Cancer Res. 73(8), 2518-2528 (2013).

43 Bai Y, Li J, Fang B et al. Phosphoproteomics identifies driver tyrosine kinases in sarcoma cell lines and tumors. Cancer Res. 72(10), 2501-2511 (2012).

44 Homsi J, Cubitt C, Daud A. The Src signaling pathway: a potential target in 
melanoma and other malignancies. Expert Opin. Ther. Targets 11(1), 91-100 (2007).

45 Montero JC, Seoane S, Ocana A, Pandiella A. Inhibition of SRC family kinases and receptor tyrosine kinases by dasatinib: possible combinations in solid tumors. Clin. Cancer Res. 17(17), 5546-5552 (2011).

46 Schrage YM, Briaire-De Bruijn IH, De Miranda NF et al. Kinome profiling of chondrosarcoma reveals SRC-pathway activity and dasatinib as option for treatment. Cancer Res. 69 (15), 6216-6222 (2009).

47 Seoane S, Montero JC, Ocana A, Pandiella A Effect of multikinase inhibitors on caspaseindependent cell death and DNA damage in HER2-overexpressing breast cancer cells. J. Natl Cancer Inst. 102(18), 1432-1446 (2010).

48 Koppikar P, Choi SH, Egloff AM et al. Combined inhibition of c-Src and epidermal growth factor receptor abrogates growth and invasion of head and neck squamous cell carcinoma. Clin. Cancer Res. 14(13), 4284-4291 (2008).

49 Dunn EF, Iida M, Myers RA et al. Dasatinib sensitizes KRAS mutant colorectal tumors to cetuximab. Oncogene 30(5), 561-574 (2011).

50 Premkumar DR, Jane EP, Pollack IF. Co-administration of NVP-AEW541 and dasatinib induces mitochondrial-mediated apoptosis through Bax activation in malignant human glioma cell lines. Int. J. Oncol. 37(3), 633-643 (2010).

51 Van Oosterwijk JG, Van Ruler MA, Briaire-De Bruijn IH et al. Src kinases in chondrosarcoma chemoresistance and migration: dasatinib sensitises to doxorubicin in TP53 mutant cells. Br. J. Cancer 109(5), 1214-1222 (2013).

- The results of this study indicate that Src family kinases are a potential target for the treatment of inoperable and metastatic chondrosarcomas, and sensitize for doxorubicin especially in the presence of TP53 mutations.

52 Schuetze SM, Wathen JK, Lucas DR et al. SARC009: Phase 2 study of dasatinib in patients with previously treated, high-grade, advanced sarcoma. Cancer 122(6), 868-874 (2016).

53 Luo J, Manning BD, Cantley LC. Targeting the PI3K-Akt pathway in human cancer: rationale and promise. Cancer Cell 4(4), 257-262 (2003)

54 Mccubrey JA, Steelman LS, Franklin RA et al. Targeting the RAF/MEK/ERK, PI3K/ $\mathrm{AKT}$ and $\mathrm{p} 53$ pathways in hematopoietic drug resistance. Adv. Enzyme Regul. 47, 64-103 (2007).

55 Myers AP, Cantley LC. Targeting a common collaborator in cancer development. Sci. Transl. Med. 2(48), 48ps45 (2010).

56 Dienstmann R, Rodon J, Serra V, Tabernero J. Picking the point of inhibition: a comparative review of PI3K/AKT/mTOR pathway inhibitors. Mol. Cancer Ther. 13(5), 1021-1031 (2014)

57 Zhang YX, Van Oosterwijk JG, Sicinska E et al. Functional profiling of receptor tyrosine kinases and downstream signaling in human chondrosarcomas identifies pathways for rational targeted therapy. Clin. Cancer Res. 19(14), 3796-3807 (2013).

58 Perez J, Decouvelaere AV, Pointecouteau T et al. Inhibition of chondrosarcoma growth by $\mathrm{mTOR}$ inhibitor in an in vivo syngeneic rat model. PLoS ONE 7(6), e32458 (2012).

- Study showing preclinical data, which indicate that mTOR inhibitor may be effective as a single agent in treating chondrosarcoma patients.

59 Bernstein-Molho R, Kollender Y, Issakov J et al. Clinical activity of mTOR inhibition in combination with cyclophosphamide in the treatment of recurrent unresectable chondrosarcomas. Cancer Chemother. Pharmacol. 70(6), 855-860 (2012).

60 Thornton KA, Chen AR, Trucco MM et al. A dose-finding study of temsirolimus and liposomal doxorubicin for patients with recurrent and refractory bone and soft tissue sarcoma. Int. J. Cancer 133(4), 997-1005 (2013).

61 O'Reilly KE, Rojo F, She QB et al. mTOR inhibition induces upstream receptor tyrosine kinase signaling and activates Akt. Cancer Res. 66(3), 1500-1508 (2006).

62 Shi Y, Yan H, Frost P, Gera J, Lichtenstein A. Mammalian target of rapamycin inhibitors activate the AKT kinase in multiple myeloma cells by up-regulating the insulin-like growth factor receptor/insulin receptor substrate-1/ phosphatidylinositol 3-kinase cascade. Mol. Cancer Ther. 4(10), 1533-1540 (2005).

63 Wan X, Harkavy B, Shen N, Grohar P, Helman LJ. Rapamycin induces feedback activation of Akt signaling through an IGF-1R-dependent mechanism. Oncogene 26(13), 1932-1940 (2007).

64 Ryan CW, Desai J. The past, present, and future of cytotoxic chemotherapy and pathway-directed targeted agents for soft tissue sarcoma. Am. Soc. Clin. Oncol. Educ. Book doi:10.1200/EdBook_AM.33.e386 (2013) (Epub ahead of print)
65 Schoffski P, Adkins D, Blay JY et al. An open-label, Phase 2 study evaluating the efficacy and safety of the anti-IGF-1R antibody cixutumumab in patients with previously treated advanced or metastatic softtissue sarcoma or Ewing family of tumours. Eur. J. Cancer 49(15), 3219-3228 (2013).

66 Naing A, Kurzrock R, Burger A et al. Phase I trial of cixutumumab combined with temsirolimus in patients with advanced cancer. Clin. Cancer Res. 17(18), 6052-6060 (2011).

67 Naing A, Lorusso P, Fu S et al. Insulin growth factor-receptor (IGF-1R) antibody cixutumumab combined with the mTOR inhibitor temsirolimus in patients with refractory Ewing's sarcoma family tumors. Clin. Cancer Res. 18(9), 2625-2631 (2012).

68 Quek R, Wang Q, Morgan JA et al. Combination mTOR and IGF-1R inhibition: Phase I trial of everolimus and figitumumab in patients with advanced sarcomas and other solid tumors. Clin. Cancer Res. 17(4), 871-879 (2011)

69 Ho AL, Vasudeva SD, Lae M et al. PDGF receptor alpha is an alternative mediator of rapamycin-induced Akt activation: implications for combination targeted therapy of synovial sarcoma. Cancer Res. 72(17), 4515-4525 (2012).

70 Pappo AS, Vassal G, Crowley JJ et al. A Phase 2 trial of R1507, a monoclonal antibody to the insulin-like growth factor-1 receptor (IGF-1R), in patients with recurrent or refractory rhabdomyosarcoma, osteosarcoma, synovial sarcoma, and other soft tissue sarcomas: results of a Sarcoma Alliance for Research Through Collaboration study. Cancer 120(16), 2448-2456 (2014).

71 Grignani G, Palmerini E, Stacchiotti S et al. A Phase 2 trial of imatinib mesylate in patients with recurrent nonresectable chondrosarcomas expressing platelet-derived growth factor receptor-alpha or -beta: an Italian Sarcoma Group study. Cancer 117(4), 826-831 (2011).

72 Ververis K, Hiong A, Karagiannis TC, Licciardi PV. Histone deacetylase inhibitors (HDACIs): multitargeted anticancer agents. Biologics 7, 47-60 (2013).

73 Fraga MF, Ballestar E, Villar-Garea A et al. Loss of acetylation at Lys16 and trimethylation at Lys 20 of histone $\mathrm{H} 4$ is a common hallmark of human cancer. Nat. Genet. 37(4), 391-400 (2005).

74 Mann BS, Johnson JR, He K et al. Vorinostat for treatment of cutaneous manifestations of advanced primary cutaneous T-cell lymphoma. Clin. Cancer Res. 13(8), 2318-2322 (2007). 
75 Whittaker SJ, Demierre MF, Kim EJ et al. Final results from a multicenter, international, pivotal study of romidepsin in refractory cutaneous T-cell lymphoma. J. Clin. Oncol. 28(29), 4485-4491 (2010)

76 Lee HZ, Kwitkowski VE, Del Valle PL et al. FDA approval: belinostat for the treatment of patients with relapsed or refractory peripheral T-cell lymphoma. Clin. Cancer Res. 21(12), 2666-2670 (2015).

77 San-Miguel JF, Hungria VT, Yoon SS et al. Panobinostat plus bortezomib and dexamethasone versus placebo plus bortezomib and dexamethasone in patients with relapsed or relapsed and refractory multiple myeloma: a multicentre, randomised, double-blind Phase 3 trial. Lancet Oncol. 15(11), 1195-1206 (2014).

78 Di Pompo G, Salerno M, Rotili D et al. Novel histone deacetylase inhibitors induce growth arrest, apoptosis, and differentiation in sarcoma cancer stem cells. J. Med. Chem. 58(9), 4073-4079 (2015).

79 Sakimura R, Tanaka K, Yamamoto S et al. The effects of histone deacetylase inhibitors on the induction of differentiation in chondrosarcoma cells. Clin. Cancer Res. 13(1), 275-282 (2007).

80 Mottamal M, Zheng S, Huang TL, Wang G. Histone deacetylase inhibitors in clinical studies as templates for new anticancer agents. Molecules 20(3), 3898-3941 (2015).

81 Albini A, Tosetti F, Li VW, Noonan DM, Li WW. Cancer prevention by targeting angiogenesis. Nat. Rev. Clin. Oncol. 9(9), 498-509 (2012).

82 Klenke FM, Abdollahi A, Bertl E et al. Tyrosine kinase inhibitor SU6668 represses chondrosarcoma growth via antiangiogenesis in vivo. BMC Cancer 7, 49 (2007).

83 Liu GT, Chen HT, Tsou HK et al. CCL5 promotes VEGF-dependent angiogenesis by down-regulating miR-200b through PI3K/ Akt signaling pathway in human chondrosarcoma cells. Oncotarget 5(21), 10718-10731 (2014).
84 Sun X, Charbonneau C, Wei L, Yang W, Chen Q, Terek RM. CXCR4-targeted therapy inhibits VEGF expression and chondrosarcoma angiogenesis and metastasis. Mol. Cancer Ther. 12(7), 1163-1170 (2013).

85 Lee HP, Lin CY, Shih JS et al. Adiponectin promotes VEGF-A-dependent angiogenesis in human chondrosarcoma through PI3K, Akt, mTOR, and HIF-alpha pathway. Oncotarget 6(34), 36746-36761 (2015).

86 Tzeng HE, Chen PC, Lin KW et al. Basic fibroblast growth factor induces VEGF expression in chondrosarcoma cells and subsequently promotes endothelial progenitor cell-primed angiogenesis. Clin. Sci. (Lond.) 129(2), 147-158 (2015).

87 Ayala G, Liu C, Nicosia R, Horowitz S, Lackman R. Microvasculature and VEGF expression in cartilaginous tumors. Hum. Pathol. 31(3), 341-346 (2000).

88 Schrage YM, Machado I, Meijer D et al. COX-2 expression in chondrosarcoma: a role for celecoxib treatment? Eur. J. Cancer 46(3), 616-624 (2010).

89 Schoffski P. Pazopanib in the treatment of soft tissue sarcoma. Expert Rev. Anticancer Ther. 12(6), 711-723 (2012).

90 Cleton-Jansen AM, Van Beerendonk HM, Baelde HJ, Bovee JV, Karperien M, Hogendoorn PC. Estrogen signaling is active in cartilaginous tumors: implications for antiestrogen therapy as treatment option of metastasized or irresectable chondrosarcoma. Clin. Cancer Res. 11(22), 8028-8035 (2005).

91 Meijer D, Gelderblom H, Karperien M, Cleton-Jansen AM, Hogendoorn PC, Bovee JV. Expression of aromatase and estrogen receptor alpha in chondrosarcoma, but no beneficial effect of inhibiting estrogen signaling both in vitro and in vivo. Clin. Sarcoma Res. 1(1), 5 (2011).

92 Ashkenazi A. Directing cancer cells to self-destruct with pro-apoptotic receptor agonists. Nat. Rev. Drug Discov. 7(12), 1001-1012 (2008).
93 Ashkenazi A. Targeting death and decoy receptors of the tumour-necrosis factor superfamily. Nat. Rev. Cancer 2(6), 420-430 (2002).

94 Adams C, Totpal K, Lawrence D et al. Structural and functional analysis of the interaction between the agonistic monoclonal antibody Apomab and the proapoptotic receptor DR5. Cell Death Differ. 15(4), 751-761 (2008).

95 Jin H, Yang R, Ross J et al. Cooperation of the agonistic DR5 antibody apomab with chemotherapy to inhibit orthotopic lung tumor growth and improve survival. Clin. Cancer Res. 14(23), 7733-7740 (2008).

96 Camidge DR, Herbst RS, Gordon MS et al. A Phase I safety and pharmacokinetic study of the death receptor 5 agonistic antibody PRO95780 in patients with advanced malignancies. Clin. Cancer Res. 16(4), 1256-1263 (2010)

97 Hollmann TJ, Hornick JL. INI1-deficient tumors: diagnostic features and molecular genetics. Am. J. Surg. Pathol. 35(10), e47-e63 (2011).

98 Kim KH, Roberts CW. Targeting EZH2 in cancer. Nat. Med. 22(2), 128-134 (2016).

99 Kostine M, Cleven AH, De Miranda NF, Italiano A, Cleton-Jansen AM, Bovee JV. Analysis of PD-L1, T-cell infiltrate and HLA expression in chondrosarcoma indicates potential for response to immunotherapy specifically in the dedifferentiated subtype. Mod. Pathol. doi:10.1038/modpathol.108 (2016) (Epub ahead of print).

100 Tawbi HA, Burgess M, Crowley J et al. Safety and efficacy of PD-1 blockade using pembrolizumab in patients with advanced soft tissue (STS) and bone sarcomas (BS): results of SARC028 - a multicenter Phase II study. 2016 ASCO Annual Meeting, Oral Abstract Session, Sarcoma. Chicago, IL, USA, 3-7 June 2016.

•. Preliminary results of a Phase II trial of pembrolizumab in patients with advanced soft tissue and bone sarcomas. 